\title{
Epidemiological Correlations Between Head and Neck Cancer and Hepatitis B Core Antibody Positivity
}

\author{
MAI FUKUSHIMA KOMORI ${ }^{1}$, TAKUJI KIMURA ${ }^{2}$, SHIN KARIYA ${ }^{3}$, TOMOO ONODA ${ }^{4}$, SEIKO TAKEDA ${ }^{1}$, \\ NOBUYOSHI MIZUKAWA ${ }^{5}$, SEIJI IIDA ${ }^{1}$, YOSHIHIRO KIMATA ${ }^{6}$ and KAZUNORI NISHIZAKI ${ }^{3}$ \\ ${ }^{1}$ Department of Oral and Maxillofacial Reconstructive Surgery, \\ Okayama University Graduate School of Medicine, Dentistry and Pharmaceutical Sciences, Okayama, Japan; \\ ${ }^{2}$ Department of Oral and Maxillofacial Surgery, Okayama University Hospital, Okayama, Japan; \\ ${ }^{3}$ Department of Otolaryngology-Head and Neck Surgery, Okayama University Graduate School of Medicine, \\ Dentistry and Pharmaceutical Sciences, Okayama, Japan; \\ ${ }^{4}$ Onoda Ear, Nose and Throat Clinic, Tamano, Japan; \\ ${ }^{5}$ Department of Oral and Maxillofacial Reconstructive Surgery, Okayama University Hospital, Okayama, Japan; \\ ${ }^{6}$ Department of Plastic and Reconstructive Surgery, Okayama University Graduate School of Medicine, \\ Dentistry and Pharmaceutical Sciences, Okayama, Japan
}

\begin{abstract}
Background/Aim: Hepatitis B core (HBc) antibody positivity indicates a history of hepatitis $B$ virus $(H B V)$ infection and latent infection. Patients and Methods: We conducted a retrospective case-control study of 512 and 495 head and neck cancer $(H N C)$ and non-HNC patients treated at the Okayama University Hospital, Head and Neck Cancer Center from 20082017. Demographic data and risk factors that might affect HNC diagnosis were analyzed to assess their effects. Results: Cancer diagnosis was found to correlate with HBc antibody positivity [odds ratio $(O R)=1.50,95 \%$ confidence interval $(C I)=1.09-2.08$ ], smoking (OR=3.03, 95\%CI=2.16-4.25), and a previous history of cancer (OR=4.12, 95\% CI=2.79-6.09). The HBs antigen positivity rate in both groups was very close to that observed in the general Japanese population. The $\mathrm{HBC}$ antibody positivity rate was very high only in the HNC group. Conclusion: HBc antibody positivity and $H N C$ are epidemiologically correlated.
\end{abstract}

In Japan, approximately $1,294,000$ individuals $(1.02 \%$ of the population) are chronically infected with the hepatitis B virus (HBV) (1). Despite the implementation of infection prevention

This article is freely accessible online.

Correspondence to: Mai Fukushima Komori, Department of Oral and Maxillofacial Reconstructive Surgery, Okayama University Graduate School of Medicine, Dentistry and Pharmaceutical Sciences, 2-5-1, Shikata-cho, Kita-ku, Okayama-city, Okayama 700-8558, Japan. Tel: +81 862356697, Fax: +81 862356698, e-mail: de19040@s.okayama-u.ac.jp

Key Words: Hepatitis B virus, head and neck cancer, HBc antibody, multivariate analysis. measures, such as blood transfusion screening, first implemented in 1972, and the prohibition of injection syringe and needle reuse that began in 1988, the expected significant decrease in the number of $\mathrm{HBV}$-infected individuals did not occur. The recent epidemiologic indication of horizontal HBV infection in infants led to the suggestion that HBV might be transmitted not only via direct contact with blood, mucous, and secreted fluids (i.e. via maternal transmission, intercourse, and medical treatment), but also during daily encounters with bleeding and exudative skin disorders. Therefore, a periodic neonatal vaccination was implemented, beginning in October 2016 in a country-dependent manner, in addition to the standard infection prevention.

Hepatitis virus infection is known to promote chronic hepatitis and liver cirrhosis and contribute to liver carcinogenesis. The mechanisms underlying hepatitis $\mathrm{C}$ virus (HCV)-related carcinogenesis are well-established; HCV directly induces carcinogenesis by its DNA and nonstructural proteins, and indirectly supports carcinogenesis by causing chronic inflammation and a consequent accumulation of genetic mutations (2).

Oral lichen planus, a precancerous condition that may progress to oral squamous cell carcinoma, is one extrahepatic symptom of HCV infection $(3,4)$. In addition, the results of a retrospective case-control study conducted by Mahale et al. suggested that HCV might affect the incidence of head and neck cancer (HNC) (5). Cohort studies in the USA have found a higher incidence, associated mortality, and diagnosis of many types of non-hepatic cancers at younger ages among $\mathrm{HCV}$-infected individuals relative to the general population (6). In contrast, the mechanisms underlying HBV-related carcinogenesis remain unknown, although this virus is also expected to exert both direct and indirect oncogenic effects. 
The incidence of HNC has increased gradually over the past 20 to 30 years (7). In addition, co-incident hepatitis infection can have important implications for $\mathrm{HNC}$ treatment. Clinically, HBV infection during cancer chemotherapy is problematic even if hepatitis B surface (HBs) antigen is negative, and the reactivation of $\mathrm{HBV}$ in $\mathrm{HBs}$ antigenpositive patients and in some HBs antigen-negative patients can cause acute hepatitis B (8). As a result, all patients treated for $\mathrm{HNC}$ at the Okayama University Hospital are screened for hepatitis virus infection at the time of hospitalization. Furthermore, other viruses such as the human papilloma virus (HPV) can also cause HNCs, including oropharyngeal squamous cell carcinomas $(9,10)$. The treatment plans are often dependent on the HPV infection status because of its high sensitivity to chemotherapy.

Limited data is available to explain the potential link between hepatitis virus infection and non-liver cancer diagnosis, and few studies have investigated this association in patients with HNC. In addition, the region and degree of involvement have not been investigated in detail. In this study, we investigated the possibility that HBV and HCV affect the incidence of HNC. In addition, we examined the relationship of infection with other carcinogenic risk factors, such as a previous history of cancer, smoking, age, and sex. As carcinogenesis is partly dependent on country and area, this study aimed to obtain Japanese-specific data from as many patients as possible.

\section{Patients and Methods}

Search strategy and selection criteria. This retrospective casecontrol study enrolled patients diagnosed with $\mathrm{HNC}$ who had been admitted to the Okayama University Hospital Head and Neck Cancer Center (Dept. of Otolaryngology-Head and Neck Surgery, Dept. of Plastic and Reconstructive Surgery, and Dept. of Oral and Maxillofacial Reconstructive Surgery) from 2008 to 2017. The diagnostic region was selected with reference to the General Rules for Clinical Studies on Head and Neck Cancer, fifth edition by the Japan Society of Clinical Oncology (2012) (11). The control group comprised non-HNC patients who were admitted to the Departments of Otolaryngology, Plastic Surgery, and Oral Surgery during the study period.

All patients who underwent hepatitis virus screening and were older than 35 years were considered eligible to participate; those who refused were excluded. The criterion of age older than 35 years was based on the timing of measures to prohibit injection syringe and needle reuse and to implement hepatitis virus screening. Additionally, this age is similar to the reported age at which carcinogenesis occurs. Patient data were collected via virus screening, blood tests, and questionnaires conducted at the time of the initial visit or diagnosis.

The study was approved by the institutional review board of Okayama University (Trial Registry number: 1604-016). As this study was a retrospective evaluation of the patients' information, it did not involve more than minimal risk to the subjects and used anonymized data; the requirement for informed consent was waived.
Table I. Region of head and neck cancer.

\begin{tabular}{lcc}
\hline Region & No. of patients & $(\%)$ \\
\hline Tongue & 75 & $(14.69)$ \\
Lip & 2 & $(0.39)$ \\
Floor of mouth & 14 & $(2.73)$ \\
Upper gum & 13 & $(2.53)$ \\
Lower gum & 27 & $(5.27)$ \\
Palate & 7 & $(1.37)$ \\
Cheek mucosa & 14 & $(2.73)$ \\
Nasopharynx & 10 & $(1.95)$ \\
Oropharynx & 57 & $(11.13)$ \\
Hypopharynx & 120 & $(23.44)$ \\
Larynx & 80 & $(15.63)$ \\
Nasal cavity and accessory sinus & 30 & $(5.86)$ \\
Major salivary gland & 26 & $(5.08)$ \\
Thyroid & 12 & $(2.34)$ \\
Esophagus & 9 & $(1.76)$ \\
Auditory organ & 11 & $(2.15)$ \\
Parapharyngeal space & 1 & $(0.2)$ \\
Others & 4 & $(0.78)$ \\
\hline Total & 512 &
\end{tabular}

Table II. Disease of control group.

\begin{tabular}{lcc}
\hline Disease & No. of patients & $(\%)$ \\
\hline Jaw deformities & 13 & $(2.63)$ \\
Sialolithiasis & 2 & $(0.40)$ \\
Benign tumor & 19 & $(3.84)$ \\
Cyst & 30 & $(6.06)$ \\
Sinusitis & 218 & $(44.04)$ \\
Fungal sinusitis & 32 & $(6.46)$ \\
Deflected nasal septum & 20 & $(4.04)$ \\
Allergic rhinitis & 10 & $(2.02)$ \\
Epistaxis & 7 & $(1.41)$ \\
Otitis media & 69 & $(13.94)$ \\
Hearing loss & 36 & $(7.27)$ \\
Méniére's disease & 7 & $(1.41)$ \\
Facial palsy & 3 & $(0.61)$ \\
Peritonsillitis & 14 & $(2.83)$ \\
Sleep apnea syndrome & 3 & $(0.61)$ \\
Others & 12 & $(2.42)$ \\
\hline Total & 495 & \\
\hline
\end{tabular}

aBenign tumors exclude precancerous lesions.

Information disclosure documents have been created and posted.

For this study, the endpoint was the diagnosis of HNC, and the main explanatory variables were hepatitis virus infection and present infection status. Other explanatory variables included age, sex, primary tumor site (stage and histopathology), liver disorders (presence or absence), diabetes mellitus (presence or absence), blood transfusion history (present or absent), alcohol consumption habits, cigarette smoking status, body mass index, and a previous history of 
cancer (presence or absence). Liver disorder was defined as an aspartate aminotransferase (AST) value of $\geq 36 \mathrm{U} / 1$, alanine transaminase (ALT) value of $\geq 43 \mathrm{U} / 1$, and $\gamma$-glutamyltransferase $(\gamma$ GT) value of $\geq 61 \mathrm{U} / \mathrm{l}$. Patients receiving treatment for diabetes and patients with a glycated hemoglobin level $>6.5 \%$ were considered diabetic. Regarding alcohol consumption, a sake index was determined from the equivalent amount of alcohol consumed per day and the number of drinking years. However, as few patients provided accurate responses regarding the amount of alcohol consumed and the number of years to accurately calculate their sake index, and the subjective opinion of the doctor who interviewed the patient was included, the sake index was excluded. Patients who smoked more than 20 cigarettes per day for $>1$ year were considered smokers (12).

Statistical analysis. Variables for the multivariate analysis were selected based on the results of a univariate analysis. Sex was selected as a basic demographic factor, and hepatitis B core ( $\mathrm{HBc})$ antibody status was selected as a measure of previous infection because it was positively correlated with carcinogenesis in the univariate analysis. In addition, smoking was considered as the most important risk factor for $\mathrm{HNC}$, and it was selected as an explanatory variable (12). Diabetes was included because it has been previously reported as a risk factor for carcinogenesis (13). Furthermore, blood transfusion history was excluded because several patients had an unknown status, according to questionnaire responses. AST was selected as an index of liver disorder.

After assessing the univariate relationships between possible risk factors and $\mathrm{HNC}$ diagnosis, we evaluated multivariate relationships using logistic regression models with the above-described variables after excluding all cases with missing values $(n=973)$. Here, we calculated the odds ratios (ORs) and corresponding 95\% confidence intervals (CIs) for HNC diagnosis. A $p$-value of $<0.05$ (2-sided test) was considered statistically significant. All statistical analyses were conducted using StatMate V (ATMS, GraphPad, Inc., San Diego, CA, USA).

\section{Results}

Table I lists the regions affected by malignancies in the 512 patients comprising the HNC patient group, and Table II lists the diseases affecting the 495 patients in the control group. Table III presents the characteristics of patients in both groups. For example, the mean ages were 66.2 years [standard deviation $(\mathrm{SD})=11.7$ years] in the $\mathrm{HNC}$ group and 62.2 years ( $\mathrm{SD}=11.9$ years) in the control group. We present the age/sex distribution of each group, and the number of patients who tested positive for the $\mathrm{HBc}$ antibody, in Figures 1-4. Patients who tested positive for the HBc antibody are distributed across all age groups and both sexes and thus do not largely comprise elderly males.

Table IV presents the crude ORs of the relationships of carcinogenesis with the variables listed in Table III. Notably, the $\mathrm{OR}$ for men (versus women) was 2.84 (95\% $\mathrm{CI}=2.17-3.71)$, and that of $\mathrm{HBc}$ antibody positivity (versus negativity) was $1.58(95 \% \mathrm{CI}=1.18-2.10)$. The OR of smoking was 3.75 $(95 \% \mathrm{CI}=2.87-4.89)$, and that of a previous history of cancer was $4.86(95 \% \mathrm{CI}=3.36-7.02)$. The univariate analysis revealed a significantly higher incidence of carcinogenesis among men, patients with $\mathrm{HBc}$ antibody positivity, smokers, diabetic patients, and those with a previous history of cancer. The link between HCV infection and HNC was not statistically significant. Furthermore, although an AST $/ \gamma$-GT outlier status was significantly correlated with carcinogenesis, no correlation with ALT values was observed.

Table V lists the results of our multivariate analysis. Notably, $\mathrm{HNC}$ diagnosis was correlated with $\mathrm{HBc}$ antibody positivity, smoking, and a previous history of cancer, with respective ORs of $1.50(95 \% \mathrm{CI}=1.09-2.08), 3.03(95 \% \mathrm{CI}=2.16-4.25)$, and 4.12 $(95 \% \mathrm{CI}=2.79-6.09)$.

Table VI shows the number of patients with viral infection by diagnostic region. $\mathrm{HBc}$ antibody-positive HNC patients presented with malignancies in multiple regions.

Table VII shows the correlation between HBV and HCV infection and histopathology. Patients were classified as having squamous cell carcinoma, adenocarcinoma, or 'other', containing tumors such as undifferentiated carcinoma. We used the chi-square test to compare each group with the control group. $\mathrm{HBc}$ antibody positivity significantly differed between the control group and all the HNC histology groups; there were no other significant differences.

Next, we evaluated the multiple primary malignant tumor status in the HNC group. Multiple primary malignant tumor status was defined according to Warren and Gates (14) as a condition in which both the initial and second tumor are known to be malignant and independent of each other, and there was no possibility that one was a metastasis of the other. Of the 512 patients in the HNC group, 159 had multiple primary malignant tumors. Among patients with multiple primary malignant tumors not affecting the head and neck, the stomach was the most frequent second tumor location (41/512), followed by the colorectum (12/512) and lung (10/512). Although liver cancer is closely related to hepatitis virus infection, 6 cases were observed among the $512 \mathrm{HNC}$ cases. These patients' virus infection status is shown in Table VIII; we did not observe a significant pattern. There was 1 patient with liver cancer in the control group.

\section{Discussion}

This study of the effects of HBV infection in a Japanese population of patients with $\mathrm{HNC}$ revealed that $\mathrm{HBc}$ antibody positivity, smoking, and a previous history of cancer were significant risk factors for head and neck carcinogenesis. We note that, relative to the Japanese population, the age and sex of the HNC group were biased towards elderly people and men.

In Japan, approximately 1.3 million individuals $(1.02 \%$ of the population) are chronically infected with HBV (1). Currently, many African and Asian countries report HBs antigen positivity rates exceeding $5 \%$, in contrast to rates of $<2 \%$ in nearly all countries in the Americas, Europe, and Oceania. As described in the introduction, nosocomial hepatitis 
Table III. Characteristics of the 512 HNC patients and 495 control patients.

\begin{tabular}{|c|c|c|c|c|c|c|}
\hline & \multicolumn{2}{|c|}{$\mathrm{HNC}(\mathrm{n}=512)$} & \multicolumn{2}{|c|}{ Control $(n=495)$} & \multicolumn{2}{|c|}{ Total $(n=1007)$} \\
\hline & \multicolumn{2}{|c|}{ No. of patients (\%) } & \multicolumn{2}{|c|}{ No. of patients (\%) } & \multicolumn{2}{|c|}{ No. of patients (\%) } \\
\hline \multicolumn{7}{|l|}{ Gender } \\
\hline Male & 389 & $(75.98)$ & 261 & $(52.73)$ & 650 & $(64.55)$ \\
\hline Female & 123 & $(24.02)$ & 234 & $(47.27)$ & 357 & $(35.45)$ \\
\hline Missing data & 0 & $(0.00)$ & 0 & $(0.00)$ & 0 & $(0.00)$ \\
\hline Age, $y$, mean/SD & 66.20 & 11.66 & 62.20 & 11.9 & 64.23 & 11.95 \\
\hline Missing data & 0 & $(0.00)$ & 0 & $(0.00)$ & 0 & $(0.00)$ \\
\hline \multicolumn{7}{|l|}{ HBs antigen } \\
\hline Positive & 5 & $(0.98)$ & 5 & $(1.01)$ & 10 & $(0.99)$ \\
\hline Negative & 507 & $(99.02)$ & 490 & (98.99) & 997 & $(99.01)$ \\
\hline Missing data & 0 & $(0.00)$ & 0 & $(0.00)$ & 0 & $(0.00)$ \\
\hline \multicolumn{7}{|l|}{ HBs antibody } \\
\hline Positive & 121 & $(23.63)$ & 101 & $(20.40)$ & 222 & $(22.05)$ \\
\hline Negative & 391 & $(76.37)$ & 394 & $(79.60)$ & 785 & $(77.95)$ \\
\hline Missing data & 0 & $(0.00)$ & 0 & $(0.00)$ & 0 & $(0.00)$ \\
\hline \multicolumn{7}{|l|}{$\mathrm{HBc}$ antibody } \\
\hline Positive & 150 & $(29.30)$ & 103 & $(20.81)$ & 253 & $(25.12)$ \\
\hline Negative & 362 & $(70.70)$ & 392 & (79.19) & 754 & $(74.88)$ \\
\hline Missing data & 0 & $(0.00)$ & 0 & $(0.00)$ & 0 & $(0.00)$ \\
\hline \multicolumn{7}{|l|}{$\mathrm{HCV}$ core antigen } \\
\hline Positive & 8 & $(1.56)$ & 3 & $(0.61)$ & 11 & (1.09) \\
\hline Negative & 504 & $(98.44)$ & 492 & (99.39) & 996 & $(98.91)$ \\
\hline Missing data & 0 & $(0.00)$ & 0 & $(0.00)$ & 0 & $(0.00)$ \\
\hline \multicolumn{7}{|l|}{ HCV antibody } \\
\hline Positive & 20 & $(3.91)$ & 11 & $(2.22)$ & 31 & $(3.08)$ \\
\hline Negative & 492 & (96.09) & 484 & (97.78) & 976 & $(96.92)$ \\
\hline Missing data & 0 & $(0.00)$ & 0 & $(0.00)$ & 0 & $(0.00)$ \\
\hline \multicolumn{7}{|l|}{ AST } \\
\hline$\leq 35 \mathrm{U} / 1$ & 454 & (88.67) & 459 & (92.73) & 913 & $(90.67)$ \\
\hline$>35 \mathrm{U} / 1$ & 57 & (11.13) & 36 & $(7.27)$ & 93 & $(9.24)$ \\
\hline Missing data & 1 & $(0.20)$ & 0 & $(0.00)$ & 1 & $(0.01)$ \\
\hline \multicolumn{7}{|l|}{ ALT } \\
\hline$\leq 42 \mathrm{U} / 1$ & 475 & $(92.77)$ & 460 & $(92.93)$ & 935 & $(92.85)$ \\
\hline$>42 \mathrm{U} / 1$ & 36 & $(7.03)$ & 35 & $(7.07)$ & 71 & $(7.05)$ \\
\hline Missing data & 1 & $(0.20)$ & 0 & $(0.00)$ & 1 & $(0.01)$ \\
\hline \multicolumn{7}{|l|}{$\gamma$-GT } \\
\hline$\leq 60 \mathrm{U} / 1$ & 395 & (77.15) & 425 & $(85.86)$ & 820 & $(81.43)$ \\
\hline$>60 \mathrm{U} / 1$ & 116 & $(22.66)$ & 69 & (13.94) & 185 & (18.37) \\
\hline Missing data & 1 & $(0.20)$ & 0 & $(0.20)$ & 2 & $(0.20)$ \\
\hline \multicolumn{7}{|l|}{ Diabetes mellitus } \\
\hline No & 399 & (77.93) & 418 & (84.44) & 817 & $(81.13)$ \\
\hline Yes & 113 & $(22.07)$ & 77 & (15.56) & 190 & $(18.87)$ \\
\hline Missing data & 0 & $(0.00)$ & 0 & $(0.00)$ & 0 & $(0.00)$ \\
\hline \multicolumn{7}{|l|}{$\mathrm{BMI}^{\mathrm{a}}$} \\
\hline Underweight & 95 & (18.55) & 35 & $(7.07)$ & 130 & $(12.91)$ \\
\hline Normal range & 340 & $(66.40)$ & 336 & $(67.88)$ & 676 & $(67.13)$ \\
\hline Overweight & 77 & (15.04) & 124 & $(25.05)$ & 201 & (19.96) \\
\hline Missing data & 0 & $(0.00)$ & 0 & $(0.00)$ & 0 & $(0.00)$ \\
\hline Smoking ${ }^{\mathrm{b}}$ & & & & & & \\
\hline No & 149 & (29.10) & 292 & (58.99) & 441 & (43.79) \\
\hline Yes & 350 & $(68.36)$ & 183 & (36.97) & 533 & $(52.93)$ \\
\hline Missing data & 13 & $(2.54)$ & 20 & $(4.04)$ & 33 & $(3.28)$ \\
\hline Previous history o & & & & & & \\
\hline No & 353 & $(68.95)$ & 453 & $(91.52)$ & 806 & $(80.04)$ \\
\hline Yes & 159 & $(31.05)$ & 42 & $(8.48)$ & 201 & (19.96) \\
\hline Missing data & 0 & $(0.00)$ & 0 & $(0.00)$ & 0 & $(0.00)$ \\
\hline
\end{tabular}

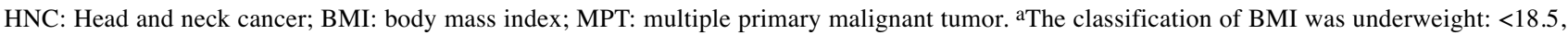
normal range $=18.50-24.99$ and overweight: $\geq 25$. bPatient who smoked more than 20 cigarettes per day for $>1$ year were considered smokers. 


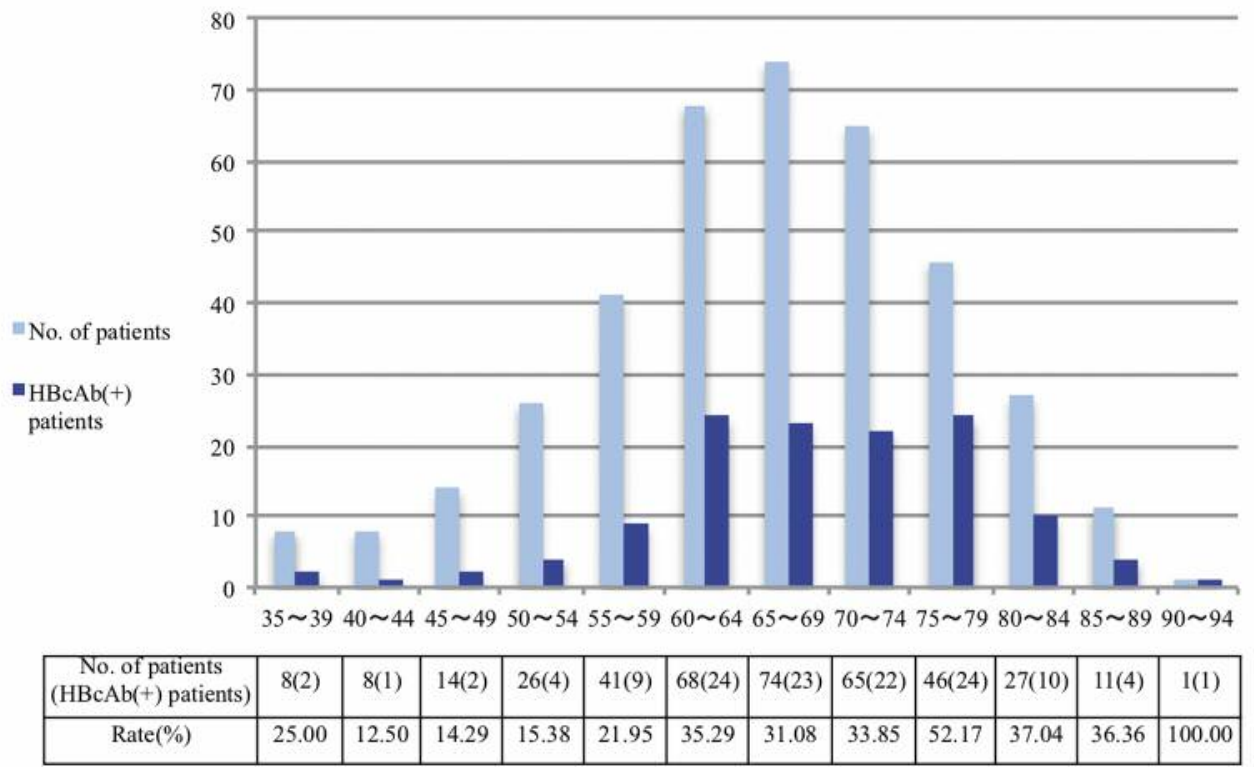

Figure 1. Age distribution of HNC group (Male) and number of HBc antibody positive patients.

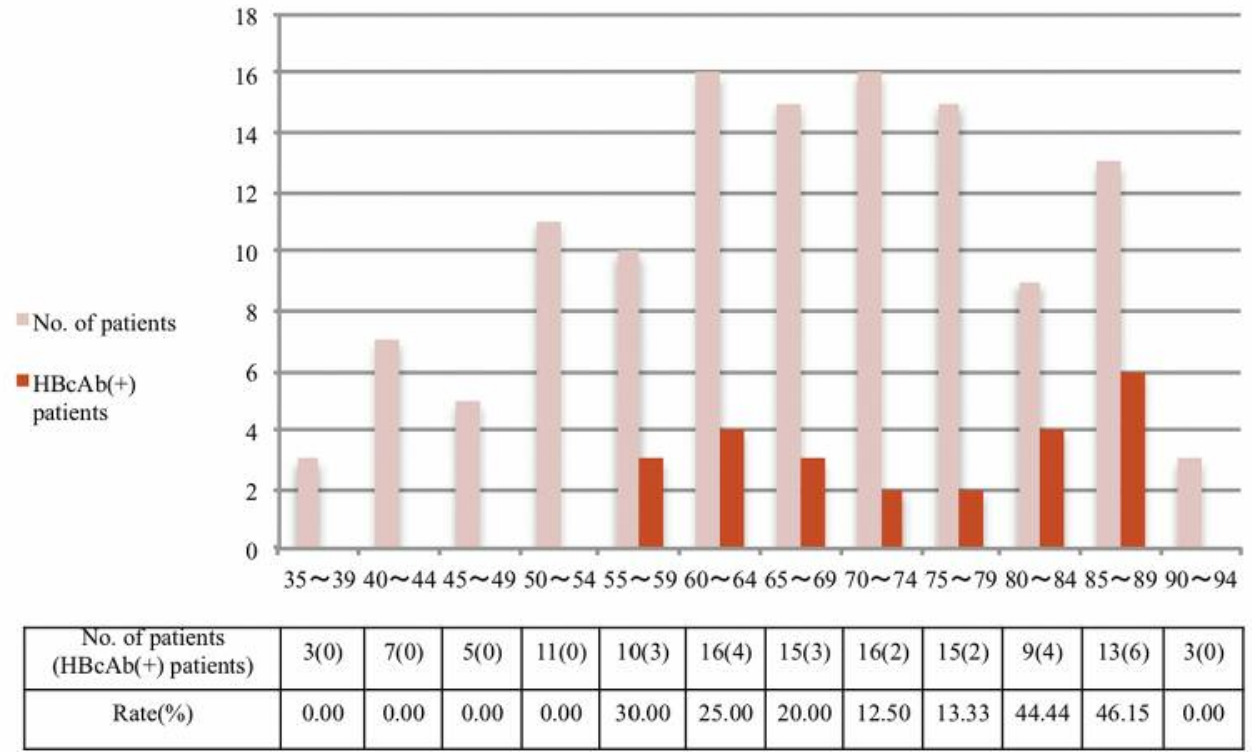

Figure 2. Age distribution of HNC group (Female) and number of HBc antibody positive patients.

virus infection was first identified in Japan in the late 1980s and remained a societal problem until the early 2000 s. Therefore, hepatitis virus screening was implemented as an important preventive strategy. Japan provides health insurance to all residents. Additionally, all hospitalized patients at Okayama University Hospital are screened for HBsAg, $\mathrm{HBsAb}$, and $\mathrm{HBcAb}$, and this study was based on the test data.
Moreover, the HBV positivity rate in the control group was similar to a previously published positivity rate in the Japanese population. Therefore, this group appears to be an appropriate control. Furthermore, the HBsAg and HBsAb positivity rates of the HNC group were similar to those in the control group and the Japanese population. Interestingly, however, we report that only the $\mathrm{HBcAb}$ positivity rate was high. 


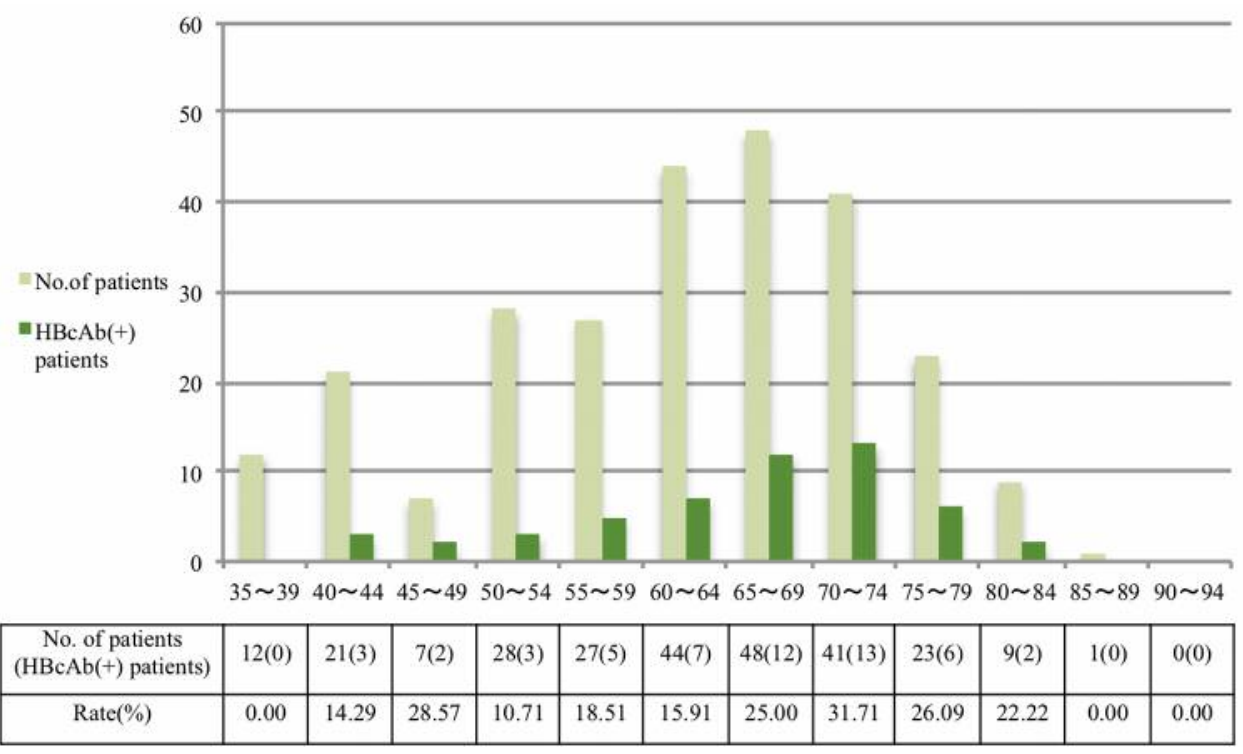

Figure 3. Age distribution of control group (Male) and number of $H B c$ antibody positive patients.

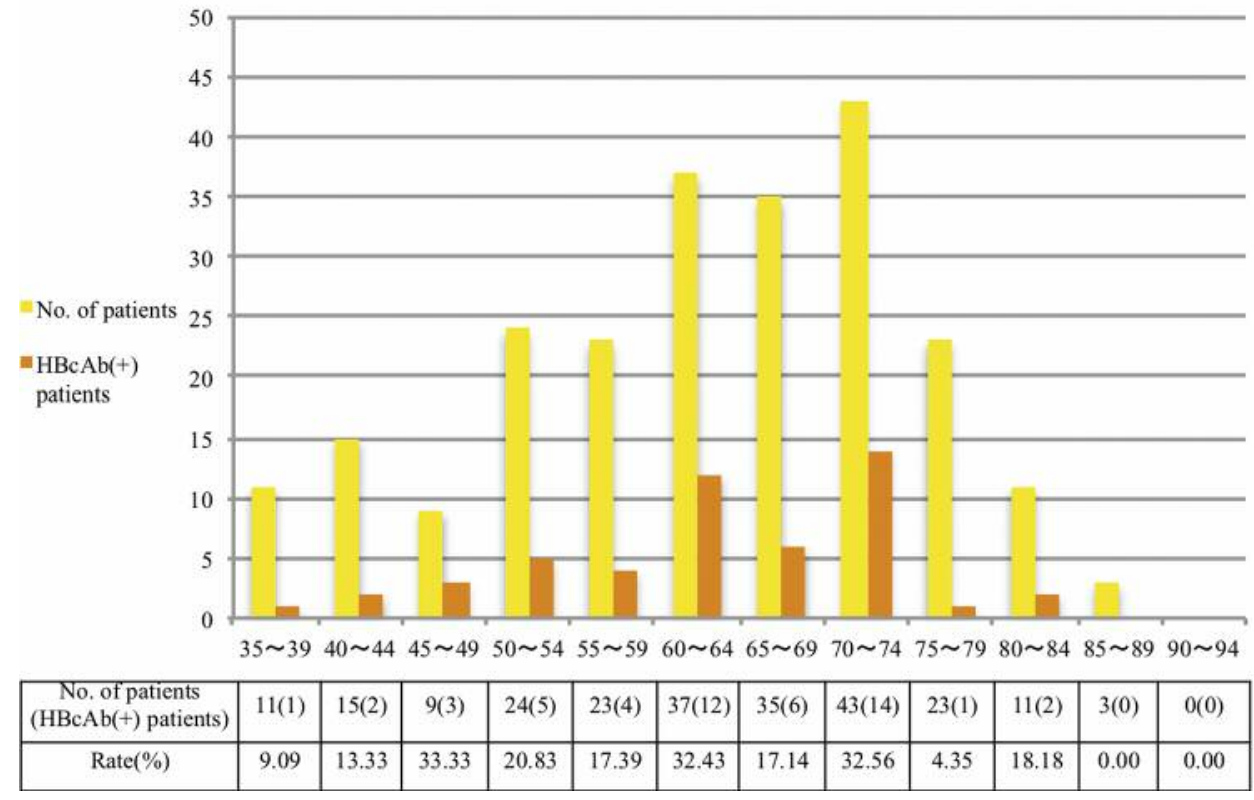

Figure 4. Age distribution of control group (Female) and number of HBc antibody positive patients.

Table IX shows the comparison between the HBs antigen positivity rate and $\mathrm{HBc}$ antibody positivity rate in this study and among the general Japanese population.

The HBs antigen positivity rate is $1.02 \%$ in Japan (1), similar to that of the control (1.3\%) and HNC (1.1\%) groups in our study. Additionally, the $\mathrm{HBc}$ antibody positivity rate is $19.72 \%$ in Japan (15), similar to that of the control group (20.81\%) in our study. In contrast, the $\mathrm{HBc}$ antibody positivity rate of the HNC group was substantially higher (29.30\%). If an individual has been widely exposed to $\mathrm{HBV}$ in the past due to their environment and behavior patterns, HBV-positive HNC patients should present with high HBs antigen and $\mathrm{HBc}$ antibody levels. We believe that our data, which only shows high rates of $\mathrm{HBc}$ antibody positivity, has not been affected by confounding factors. 
Table IV. Crude odds ratios for cancerization assosiated with heptitis viral infection and demographic variables.

\begin{tabular}{|c|c|c|c|c|c|c|c|}
\hline \multirow[b]{2}{*}{ Gender } & \multicolumn{2}{|c|}{$\begin{array}{c}\text { HNC } \\
\text { No. of patients (\%) }\end{array}$} & \multicolumn{2}{|c|}{$\begin{array}{c}\text { Control } \\
\text { No. of patients (\%) }\end{array}$} & \multirow[t]{2}{*}{ OR } & \multirow[t]{2}{*}{$(95 \% \mathrm{CI})$} & \multirow[t]{2}{*}{$p$-Value } \\
\hline & & & & & & & \\
\hline Male & 389 & (75.98) & 261 & (52.73) & 2.84 & $(2.17-3.71)$ & $2.1 \mathrm{E}-14$ \\
\hline Female & 123 & $(24.02)$ & 234 & $(47.27)$ & 1.00 & & \\
\hline \multicolumn{8}{|l|}{ HBs antigen } \\
\hline Positive & 5 & $(0.98)$ & 5 & $(1.01)$ & 0.97 & $(0.28-3.36)$ & 0.79 \\
\hline Negative & 507 & (99.02) & 490 & (98.99) & 1.00 & & \\
\hline \multicolumn{8}{|l|}{ HBs antibody } \\
\hline Positive & 121 & (23.63) & 101 & $(20.40)$ & 1.21 & $(0.90-1.63)$ & 0.25 \\
\hline Negative & 391 & (76.37) & 394 & $(79.60)$ & 1.00 & & \\
\hline \multicolumn{8}{|l|}{$\mathrm{HBc}$ antibody } \\
\hline Positive & 150 & (29.30) & 103 & $(20.81)$ & 1.58 & $(1.18-2.10)$ & 0.0024 \\
\hline Negative & 362 & (70.70) & 392 & $(79.19)$ & 1.00 & & \\
\hline \multicolumn{8}{|c|}{$\mathrm{HCV}$ core antigen } \\
\hline Positive & 8 & $(1.56)$ & 3 & $(0.61)$ & 2.60 & $(0.69-9.87)$ & 0.25 \\
\hline Negative & 504 & (98.44) & 492 & (99.39) & 1.00 & & \\
\hline \multicolumn{8}{|l|}{$\mathrm{HCV}$ antibody } \\
\hline Positive & 20 & $(3.91)$ & 11 & $(2.22)$ & 1.79 & $(0.85-3.77)$ & 0.17 \\
\hline Negative & 492 & (96.09) & 484 & $(97.78)$ & 1.00 & & \\
\hline \multicolumn{8}{|l|}{ AST } \\
\hline$\leq 35 \mathrm{U} / 1$ & 454 & (88.67) & 459 & $(92.73)$ & 1.00 & & \\
\hline$>35 \mathrm{U} / 1$ & 57 & (11.13) & 36 & $(7.27)$ & 1.60 & $(1.03-2.48)$ & 0.044 \\
\hline \multicolumn{8}{|l|}{ ALT } \\
\hline$\leq 42 \mathrm{U} / 1$ & 475 & (92.77) & 460 & $(92.93)$ & 1.00 & & \\
\hline$>42 \mathrm{U} / \mathrm{L}$ & 36 & $(7.03)$ & 35 & $(7.07)$ & 0.9960 & $(0.61-1.61)$ & 0.91 \\
\hline \multicolumn{8}{|l|}{$\gamma$-GT } \\
\hline$\leq 60 \mathrm{U} / 1$ & 395 & (77.15) & 425 & $(85.86)$ & 1.00 & & \\
\hline$>60 \mathrm{U} / 1$ & 116 & (22.66) & 69 & (13.94) & 1.81 & $(1.30-2.51)$ & 0.00048 \\
\hline \multicolumn{8}{|l|}{ Diabetes mellitus } \\
\hline No & 399 & (77.93) & 418 & $(84.44)$ & 1.00 & & \\
\hline Yes & 113 & (22.07) & 77 & $(15.56)$ & 1.54 & $(1.12-2.12)$ & 0.010 \\
\hline \multicolumn{8}{|l|}{$\mathrm{BMI}^{\mathrm{a}}$} \\
\hline Underweight & 95 & (18.55) & 35 & $(7.07)$ & 2.68 & $(1.77-4.07)$ & $2.92 \mathrm{E}-06$ \\
\hline Normal range & 340 & $(66.40)$ & 336 & $(67.88)$ & 1.00 & & \\
\hline Overweight & 77 & (15.04) & 124 & $(25.05)$ & 0.61 & $(0.44-0.85)$ & 0.0036 \\
\hline \multicolumn{8}{|l|}{ Smoking b } \\
\hline No & 149 & (29.10) & 292 & (58.99) & 1.00 & & \\
\hline Yes & 350 & (68.36) & 183 & $(36.97)$ & 3.75 & $(2.87-4.89)$ & $7.33 \mathrm{E}-23$ \\
\hline \multicolumn{8}{|c|}{ Previous history of cancer } \\
\hline No & 353 & $(68.95)$ & 453 & $(91.52)$ & 1.00 & & \\
\hline Yes & 159 & $(31.05)$ & 42 & $(8.48)$ & 4.86 & $(3.36-7.02)$ & $6.73 \mathrm{E}-19$ \\
\hline
\end{tabular}

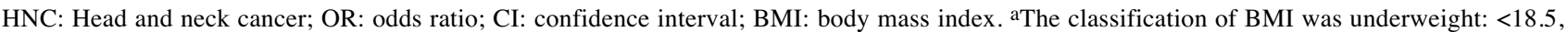
normal range: 18.50-24.99 and overweight: $\geq 25$. bPatient who smoked more than 20 cigarettes per day for $>1$ year were considered smokers.

The anatomy of the head and neck is complicated and consists of various tissue types. In this study, the HNC diagnostic regions varied, and diagnostic regions among $\mathrm{HBc}$ antibody-positive patients also varied. The main histologies of HNC are squamous cell carcinoma and adenocarcinoma. We classified patients into three groups (squamous cell carcinoma, adenocarcinoma, and others), and evaluated their relationship to clinicopathological characteristics using chisquare tests. All the HNC histology groups had significantly more $\mathrm{HBc}$ antibody-positive patients than the control group.
Among Japanese blood donors, the HCV antibody positivity rate is $1-2 \%$, and approximately 1.5 million people are thought to be infected. As mentioned above, a link between $\mathrm{HCV}$ infection and HNC has already been reported (7). Although the HNC group in the present study had a higher HCV-positive rate than the control group, this relationship was not statistically significant.

We note that Mahale et al. selected a control group of patients with three major smoking-associated cancers (lung, oesophagus, and bladder) for comparison with HNC patients (7). However, 
Table V. Adjusted odds ratios for cancerization assosiated with heptitis viral infection and demographic variables.

\begin{tabular}{|c|c|c|c|c|c|}
\hline & $\begin{array}{c}\text { HNC } \\
\text { No. of patients }\end{array}$ & $\begin{array}{c}\text { Control } \\
\text { No. of patients }\end{array}$ & OR & $(95 \% \mathrm{CI})$ & $p$-Value \\
\hline \multicolumn{6}{|l|}{ Gender } \\
\hline Male & 378 & 250 & 1.31 & \multirow[t]{2}{*}{$(0.92-1.87)$} & \multirow[t]{2}{*}{0.13} \\
\hline Female & 120 & 225 & 1.00 & & \\
\hline \multicolumn{6}{|c|}{ HBc antibody } \\
\hline Positive & 145 & 102 & 1.50 & \multirow[t]{2}{*}{$(1.09-2.08)$} & \multirow[t]{2}{*}{0.013} \\
\hline Negative & 353 & 373 & 1.00 & & \\
\hline \multicolumn{6}{|c|}{ Diabetes mellitus } \\
\hline No & 386 & 399 & 1.00 & \multirow{3}{*}{$(0.98-1.98)$} & \multirow[b]{2}{*}{0.065} \\
\hline Yes & 112 & 76 & 1.39 & & \\
\hline \multicolumn{5}{|l|}{ Smoking $^{\mathrm{a}}$} & \\
\hline No & 148 & 292 & 1.00 & \multirow{3}{*}{$(2.16-4.25)$} & \multirow[b]{2}{*}{$1.21 \mathrm{E}-10$} \\
\hline Yes & 350 & 183 & 3.03 & & \\
\hline \multicolumn{5}{|c|}{ Previous history of cancer } & \\
\hline No & 344 & 434 & 1.00 & \multirow[b]{2}{*}{$(2.79-6.09)$} & \multirow[b]{2}{*}{$1.15 \mathrm{E}-12$} \\
\hline Yes & 154 & 41 & 4.12 & & \\
\hline \multicolumn{6}{|l|}{ AST } \\
\hline$\leq 35 \mathrm{U} / \mathrm{L}$ & 441 & 441 & 1.00 & & \\
\hline$>35 \mathrm{U} / \mathrm{L}$ & 57 & 34 & 1.0 & $(0.64-1.73)$ & 0.83 \\
\hline
\end{tabular}

OR: Odds ratio; CI: confidence interval; HNC: head and neck cancer. ${ }^{\text {aPatient }}$ who smoked more than 20 cigarettes per day for $>1$ year were considered smokers.

Table VI. Diagnostic regions and serum examination of hepatitis virus.

\begin{tabular}{|c|c|c|c|c|c|c|c|c|c|c|}
\hline \multirow{2}{*}{$\frac{\text { Region }}{\text { Tongue }}$} & \multicolumn{2}{|c|}{$\operatorname{HBsAg}(+)$} & \multicolumn{2}{|c|}{$\mathrm{HBsAb}(+)$} & \multicolumn{2}{|c|}{$\mathrm{HBcAb}(+)$} & \multicolumn{2}{|c|}{$\mathrm{HCV}$ core antigen $(+)$} & \multicolumn{2}{|c|}{$\mathrm{HCV}$ antibody(+) } \\
\hline & $0 / 75$ & $0.00 \%$ & $12 / 75$ & $16.00 \%$ & $15 / 75$ & $20.00 \%$ & $1 / 75$ & $1.33 \%$ & $4 / 75$ & $5.33 \%$ \\
\hline Lip & $0 / 2$ & $0.00 \%$ & $0 / 2$ & $0.00 \%$ & $0 / 2$ & $0.00 \%$ & $0 / 2$ & $0.00 \%$ & $0 / 2$ & $0.00 \%$ \\
\hline Floor of mouth & $0 / 14$ & $0.00 \%$ & $4 / 14$ & $28.57 \%$ & $5 / 14$ & $35.71 \%$ & $0 / 14$ & $0.00 \%$ & $0 / 14$ & $0.00 \%$ \\
\hline Upper gum & $0 / 13$ & $0.00 \%$ & $4 / 13$ & $30.77 \%$ & $4 / 13$ & $30.77 \%$ & $0 / 13$ & $0.00 \%$ & $0 / 13$ & $0.00 \%$ \\
\hline Lower gum & $0 / 27$ & $0.00 \%$ & $6 / 27$ & $22.22 \%$ & $8 / 27$ & $29.63 \%$ & $1 / 27$ & $3.70 \%$ & $1 / 27$ & $3.70 \%$ \\
\hline Palate & $0 / 7$ & $0.00 \%$ & $3 / 7$ & $42.86 \%$ & $2 / 7$ & $28.57 \%$ & $0 / 7$ & $0.00 \%$ & $0 / 7$ & $0.00 \%$ \\
\hline Cheek mucosa & $0 / 14$ & $0.00 \%$ & $3 / 14$ & $21.43 \%$ & $3 / 14$ & $21.43 \%$ & $1 / 14$ & $7.14 \%$ & $1 / 14$ & $7.14 \%$ \\
\hline Nasopharynx & $0 / 10$ & $0.00 \%$ & $2 / 10$ & $20.00 \%$ & $1 / 10$ & $10.00 \%$ & $0 / 10$ & $0.00 \%$ & $0 / 10$ & $0.00 \%$ \\
\hline Oropharynx & $0 / 57$ & $0.00 \%$ & $15 / 57$ & $26.32 \%$ & $14 / 57$ & $24.56 \%$ & $1 / 57$ & $1.75 \%$ & $3 / 57$ & $5.26 \%$ \\
\hline Hypopharynx & $2 / 120$ & $1.67 \%$ & $27 / 120$ & $22.50 \%$ & $35 / 120$ & $29.17 \%$ & $2 / 120$ & $1.67 \%$ & $6 / 120$ & $5.00 \%$ \\
\hline Larynx & $1 / 80$ & $1.25 \%$ & $18 / 80$ & $22.50 \%$ & $26 / 80$ & $32.50 \%$ & $1 / 80$ & $1.25 \%$ & $4 / 80$ & $5.00 \%$ \\
\hline Nasal cavity and accessory sinus & $1 / 30$ & $3.33 \%$ & $6 / 30$ & $20.00 \%$ & $11 / 30$ & $36.67 \%$ & $1 / 30$ & $3.33 \%$ & $1 / 30$ & $3.33 \%$ \\
\hline Major salivary gland & $1 / 26$ & $3.84 \%$ & $10 / 26$ & $38.46 \%$ & $11 / 26$ & $42.31 \%$ & $0 / 26$ & $0.00 \%$ & $0 / 26$ & $0.00 \%$ \\
\hline Thyroid & $0 / 12$ & $0.00 \%$ & $3 / 12$ & $25.00 \%$ & $3 / 12$ & $25.00 \%$ & $0 / 12$ & $0.00 \%$ & $0 / 12$ & $0.00 \%$ \\
\hline Esophagus & $0 / 9$ & $0.00 \%$ & $4 / 9$ & $44.44 \%$ & $4 / 9$ & $44.44 \%$ & $0 / 9$ & $0.00 \%$ & $0 / 9$ & $0.00 \%$ \\
\hline Auditory organ & $0 / 11$ & $0.00 \%$ & $3 / 11$ & $27.27 \%$ & $4 / 11$ & $36.36 \%$ & $0 / 11$ & $0.00 \%$ & $0 / 11$ & $0.00 \%$ \\
\hline Parapharyngeal space & $0 / 1$ & $0.00 \%$ & $0 / 1$ & $0.00 \%$ & $1 / 1$ & $100.00 \%$ & $0 / 1$ & $0.00 \%$ & $0 / 1$ & $0.00 \%$ \\
\hline \multirow[t]{2}{*}{ Others } & $0 / 4$ & $0.00 \%$ & $1 / 4$ & $25.00 \%$ & $3 / 4$ & $75.00 \%$ & $0 / 4$ & $0.00 \%$ & $0 / 4$ & $0.00 \%$ \\
\hline & $5 / 512$ & & $121 / 512$ & & $150 / 512$ & & $8 / 512$ & & $20 / 512$ & \\
\hline
\end{tabular}

HBsAg: Hepatitis B core antigen; HBsAb: hepatitis B surface antibody; HBcAb: hepatitis B core antibody; HCV: hepatitis C virus.

they stated in their paper that a cancer-free control group would be more suitable. In our study, we focused on HNC patients and selected patients with non-HNCs as a control group. Although 42 patients in the control group had a history of cancer, the remaining patients $(91.5 \%)$ were cancer-free.
Regarding $\mathrm{HBc}$ antibody positivity, cases of virus reactivation under immunodeficiency that became fulminant hepatitis have a $100 \%$ mortality rate (16), suggesting the importance of $\mathrm{HBc}$ antibody evaluation. $\mathrm{HBc}$ antibody positivity not only represents a history of infection, but also 
Table VII. Histopathological diagnosis of head and neck cancers and serum examination of hepatitis virus.

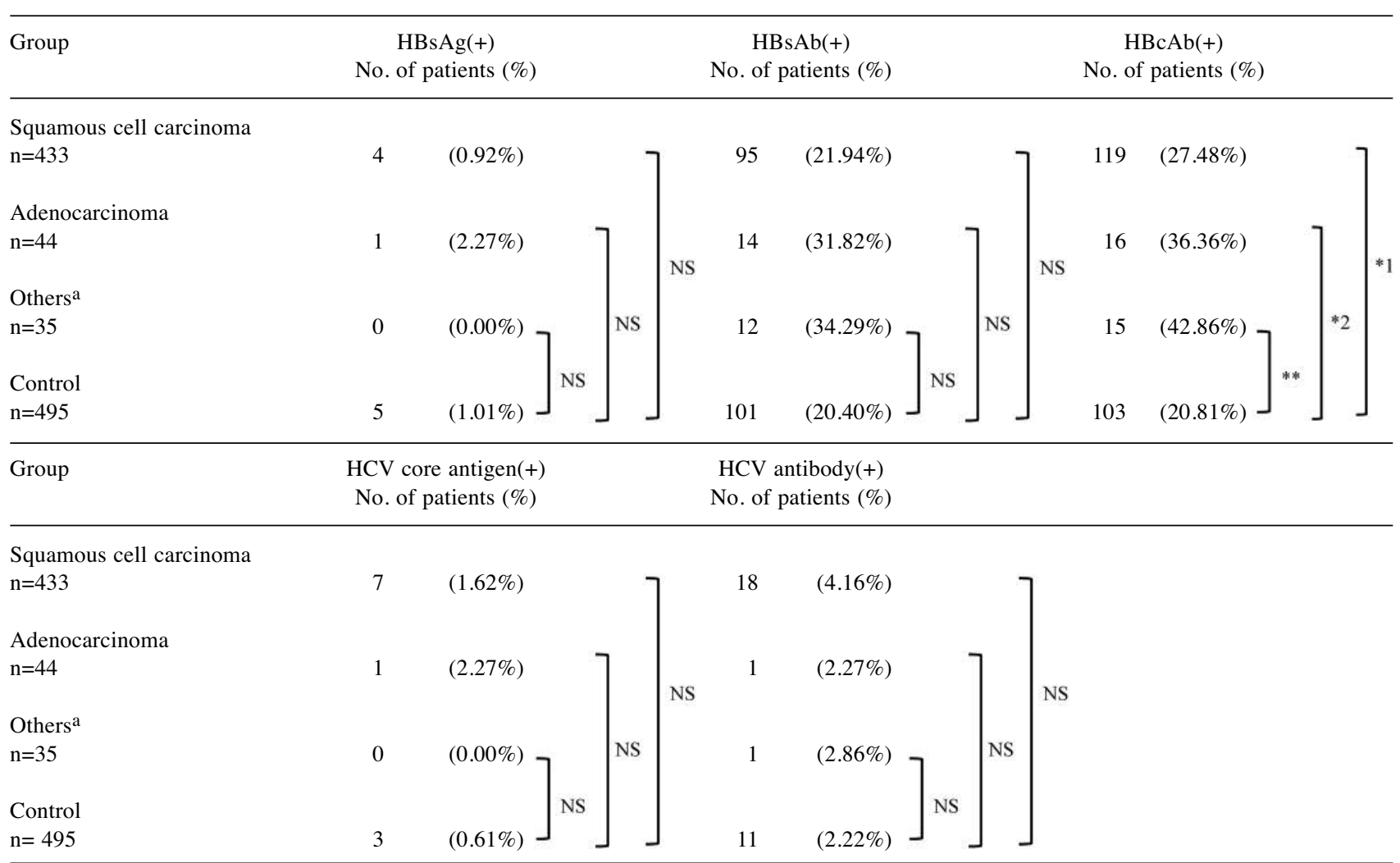

HBsAg: Hepatitis B core antigen; HBsAb: hepatitis B surface antibody; HBcAb: hepatitis B core antibody; HCV: hepatitis C virus; NS: not significant. ${ }^{* 1} p$-Value $=0.021 ; * 2$-Value $=0.028 ; * *$-Value $=0.0048$. a"Others" containing tumors such as undifferentiated carcinoma.

indicates a state of latent infection in which the HBV genome is present in hepatocytes in the form of covalently closed circular DNA. In this study, the strong correlation observed between $\mathrm{HNC}$ and latent $\mathrm{HBV}$ infection (i.e. $\mathrm{HBc}$ antibody positivity) can be explained epidemiologically. Although the mechanism of HBV-related carcinogenesis has not been elucidated, the following mechanisms should be considered. Regarding direct effects, the tumor suppressor gene TP53 might be suppressed by the HBV X protein (17), or viral genome integration might occur (18). Regarding indirect effects, the cycle of hepatocyte death and regeneration associated with chronic hepatitis could predispose the patient to malignancy $(19,20)$. Furthermore, an inflammatory mechanism in which hepatitis causes liver cirrhosis and promotes liver cancer has been conventionally mentioned and clarified with respect to hepatitis $\mathrm{C}$. However, the uncertainty of the mechanism by which hepatocellular carcinoma occurs from a latent hepatitis virus infection suggests the existence of a different mechanism, which might also promote the development of HNC. There is a possibility that $\mathrm{HBV}$ infection affects carcinogenesis through one or more of these mechanisms. Therefore, we note that improving the HBV vaccination rate may be meaningful not only for HBV prevention but also for HNC reduction.

To date, no reports have published $\mathrm{HBc}$ antibody positivity rates according to country. Notably, China (especially Hong Kong), India, Thailand, Italy, and Russia report higher rates of $\mathrm{HBs}$ antigen positivity relative to Japan, as well as higher incidences of HNC per 100,000 individuals. In comparison with the positivity rate of $1.02 \%$ in Japan, China, India, Thailand, Italy, and Russia report rates of $5.49 \%, 1.46 \%, 6.42 \%, 2.52 \%$, and $2.73 \%$, respectively. These rates correspond to respective head and neck cancer prevalence rates per 100,000 individuals of 7.6 and 2.5 in Japan, 12.4 and 5.0 in China, 17.9 and 7.9 in India, 10.6 and 4.1 in Thailand, 9.2 and 3.4 in Italy, and 13.0 and 2.7 in Russia. In contrast, other countries have low HBs antigen positivity rates. For example, Germany reported respective head and neck cancer prevalence rates of 14.5 and 4.9 per 100,000 individuals, and a $0.7 \% \mathrm{HBs}$ antigen positivity rate $(1,21)$. In other words, lifestyle habits differ among countries and regions, as do the main causes of onset 
Table VIII. Hepatitis virus status of Head and neck cancer patients with a history of liver cancer.

\begin{tabular}{lccccc}
\hline & HBsAg & HBsAb & HBcAb & $\begin{array}{c}\text { HCV core } \\
\text { antigen }\end{array}$ & $\begin{array}{c}\text { HCV } \\
\text { antibody }\end{array}$ \\
\hline Patient 1 & - & - & + & - & - \\
Patient 2 & - & - & - & - & - \\
Patient 3 & - & - & - & - & - \\
Patient 4 & + & - & + & - & - \\
Patient 5 & - & + & + & - & + \\
Patient 6 & - & - & + & - & - \\
\hline
\end{tabular}

HBsAg: Hepatitis B core antigen; HBsAb: hepatitis B surface antibody; $\mathrm{HBcAb}$ : hepatitis B core antibody; HCV: hepatitis $\mathrm{C}$ virus.

Table IX. Frequency of $H B s A g / H B c A b$ positive in $H N C$, control and Japanese.

\begin{tabular}{lrrc}
\hline & HNC & Control & Japanese prevalence \\
\hline HBsAg positive rate $(\%)$ & 0.98 & 1.01 & 1.02 \\
HBcAb positive rate (\%) & 29.30 & 20.81 & 19.72 \\
\hline
\end{tabular}

HNC: Head and neck cancer; HBsAg: hepatitis B surface antigen; $\mathrm{HBcAb}$ : hepatitis B core antibody.

(e.g. viral infection, spice usage, smoking, and alcohol habits). Therefore, further studies are necessary.

In patients with HNC, many cases of multiple primary malignant tumors in the head and neck involve squamous cell carcinomas that develop at sites of stratified squamous epithelium. In other regions (non-HNC), duplicate tumors are frequent, especially in the stomach, which has a glandular epithelium favorable for adenocarcinoma development. We agree with a previous report in which duplications of gastric cancer and HNC were described as frequent, despite differences in pathological tissue type (22). The frequency of cases involving multiple primary malignant tumors of the upper gastrointestinal tract underscores the importance of esophagogastroduodenoscopic examination during treatment for HNC.

We must note some limitations of the present study. For example, the data are affected by selection bias because we selected patients who had undergone hepatitis virus screening. Alcohol consumption was not considered, as there were few patients who provided accurate responses regarding the amount of alcohol consumed, and the subjective opinion of the doctor who interviewed the patient was included. We consider that this study provides the first link between $\mathrm{HBc}$ antibody positivity and $\mathrm{HNC}$. Although it is possible to investigate the rate of $\mathrm{HBc}$ antibody positivity in HNC patients, the frequency of $\mathrm{HNC}$ diagnosis in $\mathrm{HBc}$ antibody-positive patients has not been examined. Based on the data presented in this study, we think it is necessary to investigate the onset of $\mathrm{HNC}$ in $\mathrm{HBc}$ antibody-positive patients in subsequent studies. Furthermore, this study only addressed carcinogenic risk factors, since data from the initial visit and diagnosis were used. Later studies should address prognosis. Additional studies are needed to elucidate the underlying biological effect and carcinogenic mechanism of $\mathrm{HBc}$ antibody-positive disease.

The present study identified $\mathrm{HBc}$ antibody positivity, regular smoking, and a previous history of cancer as risk factors for HNC. Additional studies are needed to elucidate the mechanism underlying HBV-related HNC carcinogenesis.

\section{Conflicts of Interest}

All Authors of this manuscript have no conflicts of interest to declare.

\section{Authors' Contributions}

FM conceived and designed the study, collected data, performed analysis, and prepared the draft of the article. KT made critical revisions of the article for important intellectual content. KS contributed data and participated in drafting the article. OT, TS, MN, IS, KY contributed data and in the preparation of the manuscript. NK conceived and designed the study and issued final approval of the article. All Authors read and approved the final manuscript.

\section{References}

1 Schweitzer A, Horn J, Mikolajczyk RT, Krause G and Ott JJ: Estimations of worldwide prevalence of chronic hepatitis B virus infection: a systematic review of data published between 1965 and 2013. Lancet 386: 1546-1555, 2015. PMID: 26231459. DOI: 10.1016/S0140-6736(15)61412-X

2 Liang TJ and Heller T: Pathogenesis of hepatitis C-associated hepatocellular carcinoma. Gastroenterology 127: S62-S71, 2004. PMID: 15508105. DOI: 10.1053/j.gastro.2004.09.017

3 Ghodsi SZ, Daneshpazhooh M, Shahi M and Nikfarjam A: Lichen planus and Hepatitis C: a case-control study. BMC Dermatol 4: 6, 2004. PMID: 15153247. DOI: 10.1186/14715945-4-6

4 Nagao Y, Sata M, Noguchi S, Seno'o T, Kinoshita M, Kameyama T and Ueno T: Detection of hepatitis $\mathrm{C}$ virus RNA in oral lichen planus and oral cancer tissues. J Oral Pathol Med 29: 259-266, 2000. PMID: 10890556. DOI: 10.1034/j.16000714.2000.290604.x

5 Mahale P, Sturgis EM, Tweardy DJ, Ariza-Heredia EJ and Torres HA: Association Between Hepatitis C Virus and Head and Neck Cancers. J Natl Cancer Inst 108: 1-13, 2016. PMID: 27075854. DOI: $10.1093 /$ jnci/djw035

6 Allison RD, Tong X, Moorman AC, Ly KN, Rupp L, Xu F, Gordon SC and Holmberg SD: Increased incidence of cancer and cancer-related mortality among persons with chronic hepatitis C infection, 2006-2010. J Hepatol 63: 822-828, 2015. PMID: 25937437. DOI: 10.1016/j.jhep.2015.04.021 
7 Cancer Registry and Statistics. Cancer Information Service, National Cancer Center, Japan. Available at: http:// ganjoho.jp/en/professional/statistics/table_download.html [Last accessed on September 8, 2016]

8 Ikeda M, Yamamoto H, Kaneko M, Oshima H, Takahashi H, Umemoto K, Watanabe K, Hashimoto Y, Ohno I, Mitsunaga S and Okusaka T: Screening rate for hepatitis B virus infection in patients undergoing chemotherapy in Japan. Int J Clin Oncol 21: 1162-1166, 2016. PMID: 27260010. DOI: 10.1007/s10147-0160995-8

9 Adelstein DJ, Ridge JA, Gillison ML, Chaturvedi AK, D'Souza G, Gravitt PE, Westra W, Psyrri A, Kast WM, Koutsky LA, Giuliano A, Krosnick S, Trotti A, Schuller DE, Forastiere A and Ullmann CD: Head and neck squamous cell cancer and the human papillomavirus; summary of a National Cancer Institute State of the Science Meeting, November 9-10, 2008, Washington, D.C.. Head Neck 31: 1393-1422, 2009. PMID: 19787782. DOI: 10.1002/hed.21269

10 Fakhry C, Westra WH, Li S, Cmelak A, Ridge JA, Pinto H, Forastiere A and Gillison ML: Improved survival of patients with human papillomavirus-positive head and neck squamous cell carcinoma in a prospective clinical trial. J Natl Cancer Inst 100: 261-269, 2008. PMID: 18270337. DOI: 10.1093/jnci/djn011

11 Japan Society for Head and Neck Cancer: General Rules for Clinical Studies on Head and Neck Cancer, $5^{\text {th }}$ Ed. Kanehara \& Co., Tokyo, Japan, 2012.

12 Alexandrov LB, Ju YS, Haase K, Van Lpp P, Martincorena I, Nik-Zainal S, Totoki Y, Fujimoto A, Nakagawa H, Shibata T, Campbell PJ, Vineis P, Phillips DH and Stratton MR: Mutational signatures associated with tobacco smoking in human cancer. Science 354: 618-622, 2016. PMID: 27811275. DOI: 10.1126/ science.aag0299

13 Goto A, Noto H, Noda M, Ueki K, Kasuga M, Tajima N, Ohashi K, Sakai R, Tsugane S, Hamajima N, Tajima K, Imai K and Nakagama H: Report of the Japan Diabetes Society (JDS)/Japanese Cancer Association (JCA) Joint Committee on Diabetes and Cancer, Second Report. Diabetol Int 7: 12-15, 2016. PMID: 30603237. DOI: 10.1007/s13340-016-0257-z

14 Warren S and Gates O: Multiple primary malignant tumors. Am J Cancer 16: 1358-1414, 1932.
15 Kusumoto S, Tanaka Y, Mizokami M and Ueda R: Reactivation of hepatitis B virus following systemic chemotherapy for malignant lymphoma. Int J Hematol 90: 13-23, 2009. PMID: 19544079. DOI: $10.1007 / \mathrm{s} 12185-009-0359-5$

16 Umemura $\mathrm{T}$ and Kiyosawa $\mathrm{K}$ : Fatal HBV reactivation in a subject with anti-HBs and anti-HBc. Intern Med 45: 747-748, 2006. PMID: 16847362. DOI: 10.2169/internalmedicine.45.0158

17 Tamori A, Yamanishi Y, Kawashima S, Kanehisa M, Enomoto M, Tnaka H, Kubo S, Shiomi S and Nishiguchi S: Alteration of gene expression in human hepatocellular carcinoma with integrated hepatitis B virus DNA. Clin Cancer Res 11: 5821-5826, 2005. PMID: 16847362. DOI: 10.1158/1078-0432.CCR-04-2055

18 Geng M, Xin X, Bi LQ, Zhou LT and Liu XH: Molecular mechanism of hepatitis $B$ virus $X$ protein function in hepatocarcinogenesis. World J Gastroenterol 21: 10732-10738, 2015. PMID: 26478665. DOI: 10.3748/wjg.v21.i38.10732

19 Jiang S, Yang Z, Li W, Li X, Wang Y, Zhang J, Xu C, Chen P, Hou J, McCrae MA, Chen X, Zhuang H and Lu F: Re-evaluation of the carcinogenic significance of hepatitis B virus integration in hepatocarcinogenesis. PLoS One 7: e40363, 2012. PMID: 22962577. DOI: 10.1371/journal.pone.0040363

20 Bonilla Guerrero R and Roberts LR: The role of hepatitis B virus integrations in the pathogenesis of human hepatocellular carcinoma. J Hepatol 42: 760-777, 2005. PMID: 15826727. DOI: $10.1016 /$ j.jhep.2005.02.005

21 Center for Cancer Control and information Services, National Cancer Center Japan. Available at: http://ci5.iarc.fr/Default.aspx [Last accessed on October 31, 2016]

22 Kimura T: Histopathological study on the latent dysplasia and carcinoma in situ of the tongue in autopsy materials. J Jpn Soc Cancer Ther 31: 941-950, 1996.
Received February 28, 2020

Revised March 17, 2020

Accepted March 18, 2020 